\title{
Spatial association of public sports facilities with body mass index in Korea
}

\author{
Eun Jin Han, Kiyeon Kang, So Young Sohn \\ Department of Information and Industrial Engineering, Yonsei University, Seoul, Republic of Korea
}

\begin{abstract}
Governments and also local councils create and enforce their own regional public health care plans for the problem of overweight and obesity in the population. Public sports facilities can help these plans. In this paper, we investigated the contribution of public sports facilities to the reduction of the obesity of local residents. We used the data obtained from the Fifth Korea National Health and Nutrition Examination Surveys; and measured the degree of obesity using body mass index (BMI). We conducted various spatial regression analyses including the global Moran's $I$
\end{abstract}

Correspondence: So Young Sohn, D1003 room, The Fourth Engineering Building, Yonsei University, 50 Yonsei-ro Seodaemun-gu, Seoul, 03722, Republic of Korea.

Tel.:+82.2.2.123.4014 - Fax:+82.2.364.7807.

E-mail: sohns@yonsei.ac.kr

Key words: Knhanes; Public sports facilities; Sociodemographic characteristics; BMI; Spatial autoregressive model.

Acknowledgements: this research - Geospatial Big Data Management, Analysis and Service Platform Technology Development - was supported by the MOLIT (the Ministry of Land, Infrastructure and Transport), Korea, under the national spatial information research program supervised by the KAIA (Korean Agency for Infrastructure Technology Advancement) (18NSIP-B081011-05). This research used raw data from the KNHANES V-3 surveyed by the Korea Centers for Disease Control and Prevention (Korea CDC). Sang Wook Park participated in the early stage of this analysis.

Contributions: the authors contributed equally.

Conflict of interest: the authors declare no potential conflict of interest.

Funding: funding from Ministry of Land, Infrastructure and Transport/Korean Agency for Infrastructure Technology Advancement.

Received for publication: 4 January 2017.

Revision received: 11 November 2017.

Accepted for publication: 14 November 2017.

(C) Copyright E.J. Han et al., 2018

Licensee PAGEPress, Italy

Geospatial Health 2018; 13:542

doi:10.4081/gh.2018.542

This article is distributed under the terms of the Creative Commons Attribution Noncommercial License (CC BY-NC 4.0) which permits any noncommercial use, distribution, and reproduction in any medium, provided the original author(s) and source are credited. test and local indicators of spatial autocorrelation analysis finding that there exists spatial dependence in the error term of spatial regression model for BMI. However, we also observed that the number of local public sports facilities is not significantly related to local BMI. This result can be caused by the low utilization ratio and an unbalanced spatial distribution of local public sports facilities. Based on our findings, we suggest that local councils need to improve the quality of public sports facilities encouraging the establishment of preferred types of pubic sports facilities.

\section{Introduction}

The obese percentage of the world population is increasing (OECD, 2013; Han et al., 2016). Obesity can contribute to the development of several diseases, including cardiovascular disease, cancer, and type-2 diabetes. Low energy expenditure and high food intake lead to obesity (Kumanyika et al., 2002). As energy expenditure and food intake are potentially influenced by socioeconomic status (SES), many studies have investigated the relationships between the degree of obesity measured in terms of body mass index (BMI) and SES, such as age, gender, region of residence and education (Addo et al., 2009; Beydoun and Wang, 2009; Stommel and Schoenborn, 2010). Research has lately been expanded to investigating the relation between obesity and other factors, such as alcohol consumption (Kang et al., 2013), smoking (Pouliou and Elliott, 2010), leisure activity (Ross et al., 2007), and stress (Mak et al., 2015).

Ordinary least squares (OLS) regression analysis has been used to identify these relationships (Hojgaard et al., 2008). However, after recent studies identified that obesity has spatial dependence, spatial analyses were conducted to further understand its spatial dependence (Drewnowski et al., 2009; Duncan et al., 2012). Such studies used the global Moran's I statistic (Chen and Wen, 2010; Drewnowski et al., 2014), the spatial error model (SEM) (Drewnowski et al., 2009; Duncan et al., 2012), the spatial lag model (SLM) (Slack et al., 2014), and the local indicator of spatial autocorrelation (LISA) (Myers et al., 2015). From these empirical studies, spatial regression analyses have taken into account the spatial dependence to investigate the relationship between obesity and several factors, such as SES (age, gender, and employment), educational level, food environment, and smoking. However, these studies did not focused on the relationship with variables concerning local health policy which could also play a role.

Many governments and local councils have developed and enforced their own regional public health care plans (Bullough et al., 2015). In Korea, regional public health and medical care plans are outlined in the Regional Public Health Act (Kang and Sohn, 2016). One of these care plans is Management of public sports 
facilities. The term public sports facility is defined as a physical environment located in an area. These facilities are established to promote healthy lifestyles of local people via effective and safe physical activities.

In this study, we investigated in a local area whether public sports facilities established in lieu of regional public health plan have indeed contributed to the reduction of the obesity of adult residents. Various sociodemographic variables were used as control variables. Our spatial analysis consisted of three steps: calculating the global Moran's I statistic, creating the LISA and comparing different types of spatial regressions using the spatial lag model; the spatial Durbin model; the spatial error model; the spatial Durbin error model; and the general spatial model. We utilized the data obtained from the Fifth Korea National Health and Nutrition Examination Surveys (KNHANES V-3) conducted in 2012.

\section{Literature review}

Policies for encouragement of participation in sports have been implemented in many countries (Downward et al., 2009; Sotiriadou, 2009; Downward and Rasciute, 2010). The importance of sports infrastructures has been emphasized for the encouragement of participation in various sports (Wicker et al., 2013). To verify the effect of such infrastructures, many researchers have analyzed the relationship between sport infrastructure and sports participation by considering various variables.

Sallis et al. (2000) reviewed a broad range of literature investigating what make people involved in physical activities. As a result, the authors concluded that high accessibility of facilities or programmes influences the physical activity of children and adolescents positively. However, also conflicting opinions on the effect of participation in sports have been heard. Niclasen et al. (2012) showed that proximity to sports facility is positively associated with a high level of vigorous physical activity, while it is negatively associated with moderate to vigorous physical activity in Greenlandic adolescents. In Dutch adolescents, Prin et al. (2010) concluded that access to sports facilities is not a sufficient condition but a precondition to promote physical activity. Furthermore, although Holman et al. (1996) identified accessibility of a sports facility as an important factor in encouraging physical activity, Stahl et al. (2001) demonstrated that supportive physical environment is not associated with physical activity, and Van Lenthe (2005) stated that while residents with lower income participate more in walking and cycling in general, they participate less in sporting activities.

Individual determinants such as age, income and education level as well as proximity to sports infrastructures have also been considered as affecting participation in sport (Berger et al., 2008; Downward and Rasciute, 2010; Ruseski et al., 2011). Recently, Wicker et al. (2013) analyzed the relationship between detailed characteristics of sports infrastructures as well as the individual determinants and sporting through multi-level analyses. They considered the size of sports areas, the number of swimming pools, the number of track and field arenas and the detailed characteristics of sports infrastructures. O'Reilly et al. (2015) discussed the characteristics of the infrastructure in more detail complementing the work by Wicker et al. (2013) with added variables, such as the year it was built or renovated, the types of food services available as well as the facility size and the number of pools and rinks.

In addition, many studies aimed to identify whether the participation in sports influences on the reduction of obesity. Hojgaard et al. (2008) analyzed the relationship between individual vari- ables, including participation in sport activities and waist circumference. Since then, some researchers recognized the spatial dependence in variables representing the extent of obesity and adopted spatial regression for its study. Chen and Wen (2010) confirmed the relationship between individual variables including physical inactivity and BMI through in this way, and Slack et al. (2014) analyzed such relationships in terms of recreational, economic and health context. Many studies like these has been carried out to identify such relationship. In our study, we analyzed whether public sports facilities are positively associated with the reduction of obesity in the public policy context. Intrinsic influence of public sports facilities was analyzed after controlling for some individual determinants and considering spatial dependence of regional obesity.

\section{Materials and Methods}

\section{Survey data}

We used the survey data obtained from the KNHANES V-3 2012 provided by the Korea Centers for Disease Control and Prevention (Korea CDC). For the survey, the Korea CDC extracted 192 primary sampling units named enumeration districts from 3,479 administrative districts across the country. These data were collected based on the resident registration population in 2009 and a survey of apartment prices in 2008. Next, Korea CDC sampled 3,840 secondary sampling units, i.e. households, from the sampled enumeration districts and conducted a survey of all household members. Although the final sampling unit was the household, personal addresses are not available to the public. Therefore, in this study, data analysis was conducted at the enumeration district level. We used only the KNHANES V-3 data because the Korea CDC extracts enumeration districts differently every year. Among the data provided by the Korea CDC, we eliminated research subjects under the age of 19 in order to restrict our subjects of interest to adults. The final sample for this study was 5,436 adults consisting of 2,248 males (41.35\%) and 3,188 females (58.65\%).

\section{Variables}

All information used was self-reported by the KNHANES V-3 respondents. We used BMI, calculated as the weight in kilograms divided by the square of the height in meters, as the dependent variable. Independent variables included in the models are public sports facility variables from the Korean Statistical Information Service (KOSIS). Public sports facility variables were represented by the number of public sports facilities (as this supplies information about the absolute effect of public sports facilities) and the number of public sports facilities per 10,000 people (which provides information about the relative effect considering the population). As sociodemographic characteristic variables we used years of education, the average monthly household income and number of members in the household as these factors are usually considered as explanatory variables for BMI (Wen et al., 2010). As control variables, we set i) self-rated health status variables; ii) physical activity. For health related variables, we used average hours of sleep, waist circumference, drinking frequency and smoking status. These values were generated from answers to the KNHANES V-3 questions about health status. Drinking frequency and smoking status were used as categorical variables. The activity variables were based on the intensity, duration and frequency of physical 
activity and were represented by vigorous physical activity days, walking days, muscle-strengthening activity days and flexibility activity days.

We analyzed the spatial association of public sports facilities with BMI at the enumeration district level by re-arranging data from the individual level to the enumeration district level. For each enumeration district unit, 28.5 participants were included on average. The number of survey participants at enumeration district level is displayed in Figure 1. The summary statistics of the continuous and categorical variables at the individual level $(n=5,436$ adults) and the enumeration district level ( $\mathrm{n}=191$ units) are shown in Tables 1-4.

\section{Statistical analysis}

We conducted a three-step statistical analysis process starting with calculation of the Global Moran's $I$ statistic followed by a LISA analysis and a comparison analysis of spatial regression models. In our analysis, the global Moran's I statistic was essential. If significant, spatial dependence in the dependent variable would be implied signalling that we could proceed to the spatial regression models. After that the LISA analysis was conducted for exploratory spatial data analysis, we determined the best model to account for the relationship between BMI and the independent variables, i.e. the OLS model, the SLM model, the spatial Durbin model (SDM), the SEM model, the spatial Durbin error model (SDEM) and the general spatial model (GSM) (Anselin, 2013).

The global Moran's I statistic is used as a measure of the overall spatial autocorrelation by testing the null hypothesis that no spatial correlation exists in the distribution of the dependent variable. If the hypothesis is rejected, this statistic supports either clustering (homogeneity) or dispersion (heterogeneity). A global Moran's $I$ statistic near +1 indicates heterogeneity, while that near

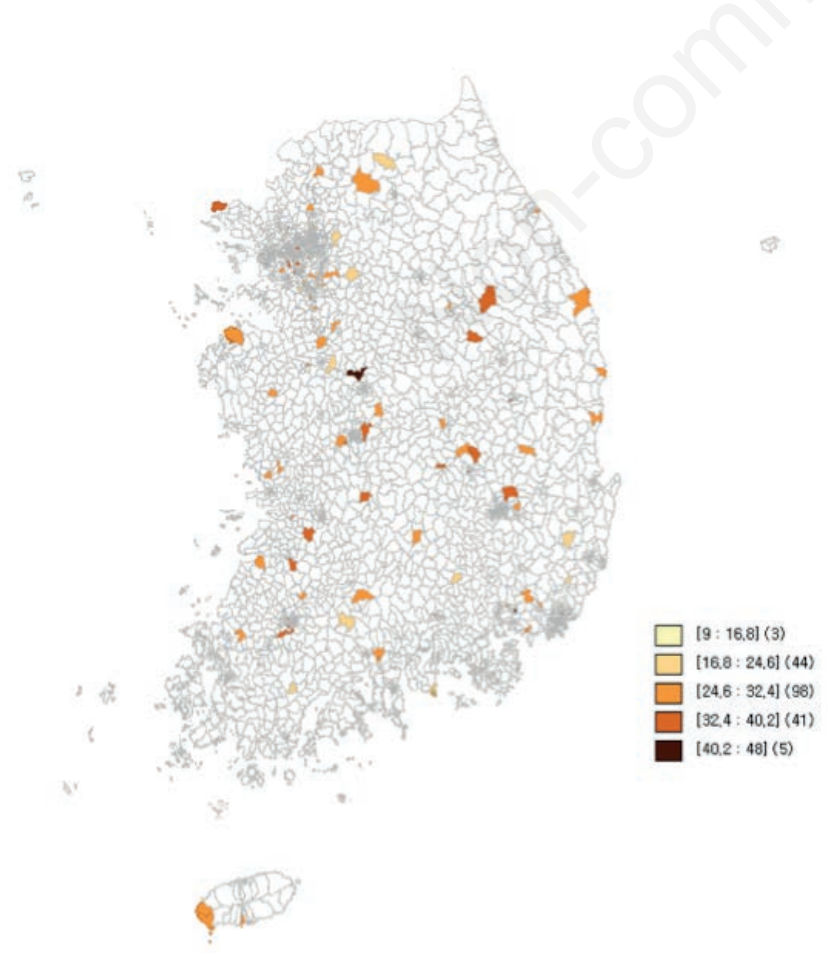

Figure 1. The number of survey participants at the enumeration district level in Korea.
-1 indicates homogeneity (Anselin and Bera, 1998). In this analysis, we constructed a row-standardized spatial weights matrix based on radial distance (threshold distance $=80 \mathrm{~km}$ ). We selected the radial distance with the most significant global Moran's $I$ statistic (i.e., that with the lowest P-value) by increasing the radial distance at $5-\mathrm{km}$ intervals.

After conducting the global Moran's I test examining the overall spatial autocorrelation, the LISA analysis was used to investigate local spatial autocorrelation (Anselin, 2004). The LISA analysis intrinsically measures the statistical correlation for the value of one area with values of nearby areas. A LISA value close to zero implies little or no statistical correlation among the neighbourhoods, while a value near +1 indicates a perfect positive spatial autocorrelation (clustered together by high or low values). A LISA value near -1 , on the other hand, means a perfect negative spatial autocorrelation (checkerboard pattern) (Moran, 1950). For each enumeration district, the relationship between BMI and mean BMI of a given neighbourhood was calculated. Using the relationship with each neighbourhood, this relation falls into four categories: i) high-high (HH) clusters categorized by high BMI values associated with high BMI neighbours; ii) low-low (LL) clusters indicating low BMI values associated with low BMI neighbours; iii) highlow (HL) outliers implying high BMI values with low BMI neigh-

Table 1. Summary statistics of the continuous variables at individual level $(n=5,436)$.

\begin{tabular}{lcccc} 
Variable & Mean & SD & Min & Max \\
BMI & 23.75 & 3.42 & 14.40 & 53.50 \\
Age & 51.19 & 16.71 & 19.00 & 89.00 \\
\hline Years of education & 11.33 & 3.81 & 6.00 & 16.00 \\
Number of members per household & 3.07 & 1.25 & 1.00 & 8.00 \\
\hline The average monthly household income & 399.25 & 750.31 & 0.00 & $16,867.00$ \\
(ten thousand won) & & & & \\
Average sleeping hours per day & 6.78 & 1.43 & 1.00 & 18.00 \\
\hline Vigorous physical activity days per week & 0.78 & 1.54 & 0 & 7.00 \\
Walking days per week & 3.81 & 2.60 & 0 & 7.00 \\
\hline Muscle-strengthening activity days per week0.77 & 1.47 & 0 & 5.00 \\
Flexibility activity days per week & 1.71 & 1.91 & 0 & 5.00 \\
\hline Waist circumference (cm) & 81.16 & 9.80 & 49.30 & 136.40 \\
\hline BMI Body mass index & & & &
\end{tabular}

Table 2. Summary statistics of the categorical variables at the individual level $(n=5,436)$.

\begin{tabular}{lcc}
\hline Variable & Frequency & $\%$ \\
Smoking status & & \\
$\quad$ Smoked less than 100 cigarettes during lifetime & 141 & 2.59 \\
Smoked more than 100 cigarettes during lifetime & 1,982 & 36.46 \\
$\quad$ Non-smoking & 3,313 & 60.95 \\
Annual drinking frequency & & \\
None & 1,656 & 30.46 \\
Less than once per month & 1,053 & 19.37 \\
Once per month & 549 & 10.10 \\
2-4 times per month & 1,119 & 20.58 \\
2-3 times per week & 702 & 12.91 \\
More than 4 times per week & 357 & 6.57 \\
\hline
\end{tabular}


Table 3. Summary statistics of the continuous variables at the enumeration district level $(n=191)$.

\begin{tabular}{|c|c|c|c|c|}
\hline Variable & Mean & SD & Min & Max \\
\hline BMI & 23.76 & 0.84 & 21.08 & 26.65 \\
\hline Age & 51.33 & 7.13 & 38.04 & 70.00 \\
\hline Years of education & 11.23 & 2.00 & 6.38 & 15.31 \\
\hline Number of members in household & 3.02 & 0.54 & 1.76 & 4.22 \\
\hline The average monthly household income (ten thousand won) & 383.59 & 239.07 & 65.50 & $1,977.08$ \\
\hline Average sleeping hours per day & 6.78 & 0.31 & 5.96 & 7.61 \\
\hline Vigorous physical activity days per week & 0.77 & 0.34 & 0.00 & 1.74 \\
\hline Walking days per week & 3.81 & 0.68 & 2.00 & 5.50 \\
\hline Muscle-strengthening activity days per week & 0.76 & 0.34 & 0.00 & 1.88 \\
\hline Flexibility activity days per week & 1.69 & 0.48 & 0.27 & 3.04 \\
\hline Waist circumference (cm) & 81.19 & 2.89 & 72.70 & 89.41 \\
\hline Number of public sports facilities & 94.27 & 70.65 & 2.00 & 320.00 \\
\hline Number of public sports facilities per 10,000 people & 3.82 & 3.87 & 0.07 & 22.75 \\
\hline
\end{tabular}

BMI, Body mass index.

bours; and iv) LH outliers, which exhibit low BMI values with high BMI neighbours. To test LISA significance, we used a Monte Carlo permutation approach. This method assumes that the spatial data are likely to be similarly observed for any location. The spatial data values are randomly shuffled across all places, and the LISA value is recalculated for each Monte Carlo permutation. The significance of the LISA analysis was determined by conducting a reference distribution over 999 random permutations. The final step included a comparison of the six regression models mentioned above and expressed as follows:

$$
\begin{gathered}
\text { OLS: } y=X \beta+\varepsilon \\
\text { SLM: } y=\rho W y+X \beta+\varepsilon, \varepsilon \sim N\left(0, \sigma^{2} I\right) \\
\text { SDM: } y=\rho W y+X \beta+W X \theta+\varepsilon, \varepsilon \sim N\left(0, \sigma^{2} I\right) \\
\text { SEM: } y=X \beta+u, u=\lambda W u+\varepsilon, \varepsilon \sim N\left(0, \sigma^{2} I\right) \\
\text { SDEM: } y=X \beta+W X \theta+u, u=\lambda W u+\varepsilon, \varepsilon \sim N\left(0, \sigma^{2} I\right) \\
\text { GSM: } y=\rho W y+X \beta+u, u=\lambda W u+\varepsilon, \varepsilon \sim N\left(0, \sigma^{2} I\right)
\end{gathered}
$$

where $y$ is an $\mathrm{n} \times 1$ vector of dependent variable (BMI in our analysis) and $X$ and $\beta$ have conformable dimensions for $k$ exogenous covariates including a constant. $\varepsilon$ is a vector of error terms; $\rho$ a coefficient on the spatial lag of the dependent variable; $W$ a $\mathrm{n} \times \mathrm{n}$ spatial weight matrix; $\theta$ the regression parameter reflecting the influence of the spatially lagged explanatory variables on variation in the dependent variable $y$; and $\lambda$ a coefficient on the spatial lag of the error term.

In order to reflect the spatial autocorrelation, various spatial regression models were used in this study (Han and Sohn, 2017). The spatial dependence was incorporated using a spatially lagged dependent variable ( $W y)$ in the SLM; using spatially lagged dependent variable $(W y)$ and independent variable $(W X)$ in the SDM; using a spatial lag of error term $(W u)$ in SEM; and using spatial lags of error term $(W u)$ and independent variable $(W X)$ in the SDEM (Anselin, 2013). The GSM is a combination of the SLM and the SEM (Anselin, 2013). In order to choose the best model, we utilized the Akaike information criterion (AIC) (Akaike, 1974; 1998) and the log-likelihood (Huelsenbeck and Crandall, 1997) of the regressions OLS, SLM, SDM, SEM, SDEM and GSM.

We used two open source softwares: GeoDa (https://spatial. uchicago.edu/software) and R (https://www.r-project.org/). GeoDa
Table 4. Summary statistics of the categorical variables at the enumeration district level $(n=191)$.

\begin{tabular}{lcc} 
Variable & Frequency & $\%$ \\
Smoking status & & \\
Smoked less than 100 cigarettes during lifetime & 0 & 0 \\
Smoked more than 100 cigarettes during lifetime & 18 & 9.42 \\
Non-smoking & 173 & 90.58 \\
Annual drinking frequency & & \\
None & 104 & 54.45 \\
Less than once per month & 26 & 13.61 \\
Once per month & 7 & 3.66 \\
2-4 times per month & 45 & 23.56 \\
2-3 times per week & 8 & 4.19 \\
More than 4 times per week & 1 & 0.52 \\
\hline
\end{tabular}

was used to figure out the spatial distribution of variables and to create LISA significance and cluster maps. R was utilized to conduct the Moran's I test, the LISA analysis and the spatial regression analysis.

\section{Results}

Moran's $I$ statistic values for the dependent variable and residual were 0.022 (P-value: 0.083) and 0.098 (P-value<0.000), respectively telling us that there existed a positive spatial autocorrelation in $\mathrm{BMI}$ and residual.

Performing the LISA analysis, we found that 41 enumeration district units $(21.47 \%)$ were spatially autocorrelated at a significance level of 0.05 . In addition, $16 \mathrm{HH}$ clusters $(8.38 \%), 7 \mathrm{HL}$ outliers $(3.66 \%), 2$ LL clusters $(1.05 \%), 16 \mathrm{LH}$ outliers $(8.38 \%)$ and 150 non-significant areas $(78.53 \%)$ were identified. The HH clusters, which indicate clustering of similarly high BMI values, were usually located in Midwest Korea. The BMI values at the enumeration district level, the LISA significance map for BMI and the LISA cluster map for BMI are displayed in Figures 2-4. When we 
compared the performance of the six models (OLS, SLM, SDM, SEM, SDEM and GSM), the SEM model was selected as the best model. This result indicated that a regression analysis of BMI in Korea should consider the spatial dependence in the error term.

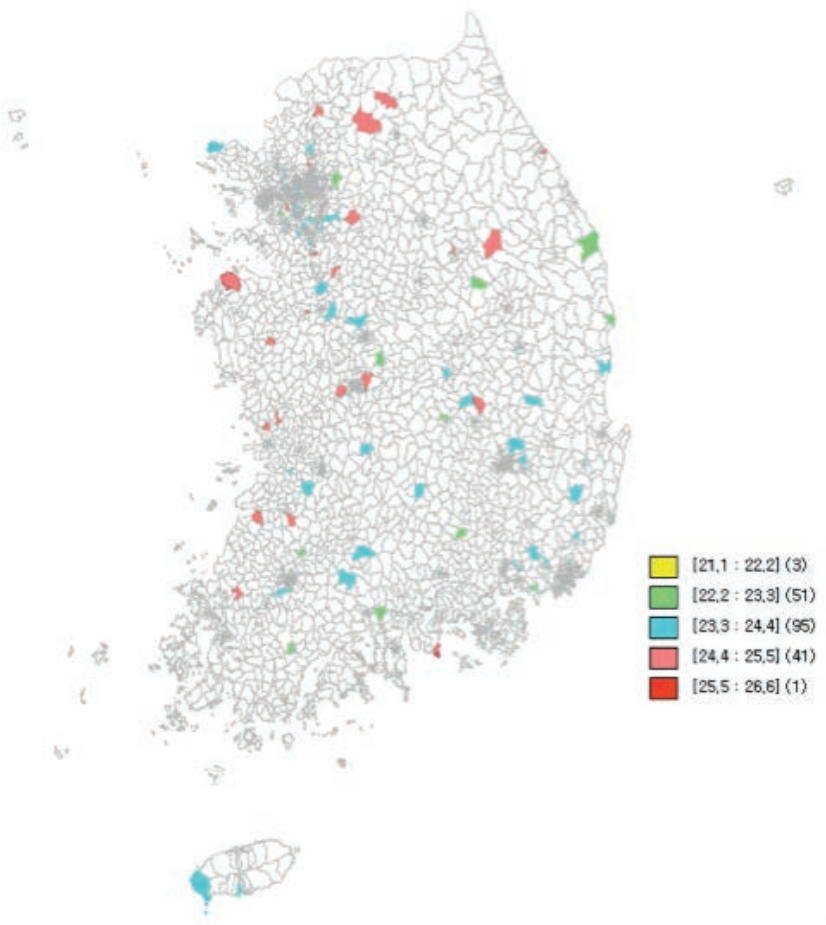

Figure 2. The body mass index value at the enumeration district level in Korea.
Table 5 shows the comparison of the six regression models and Table 6 shows the results of OLS and SEM.

In the OLS model, the number of Members in household was found to be statistically significant at the $10 \%$ level; however, this

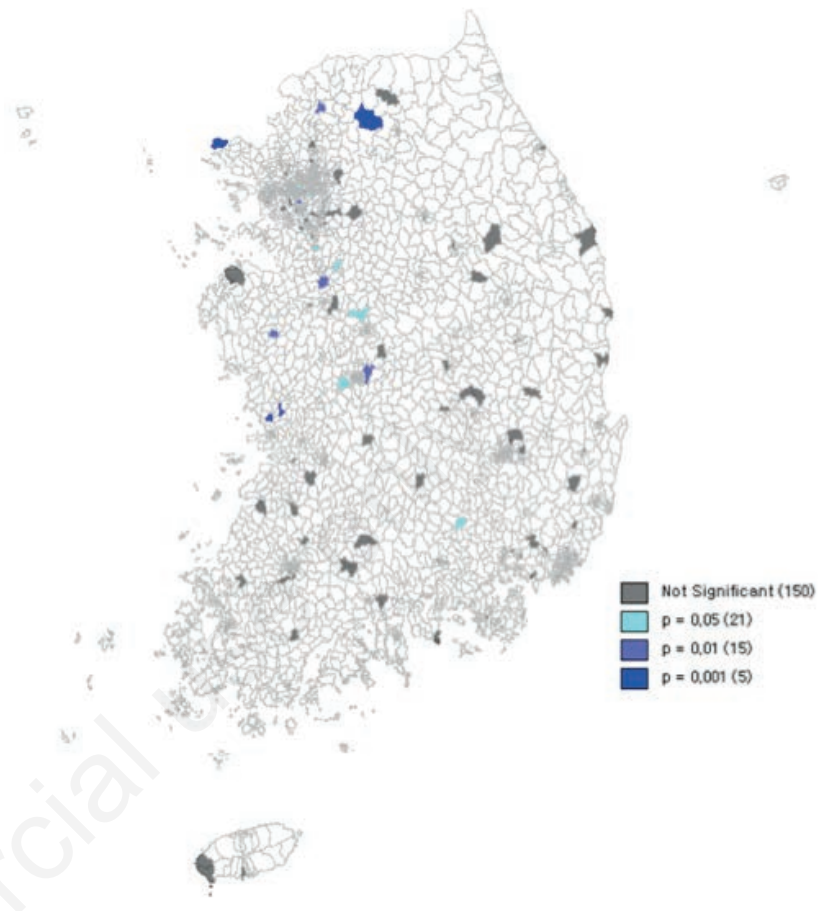

Figure 3. The local indicator of spatial autocorrelation significance map for body mass index in Korea.

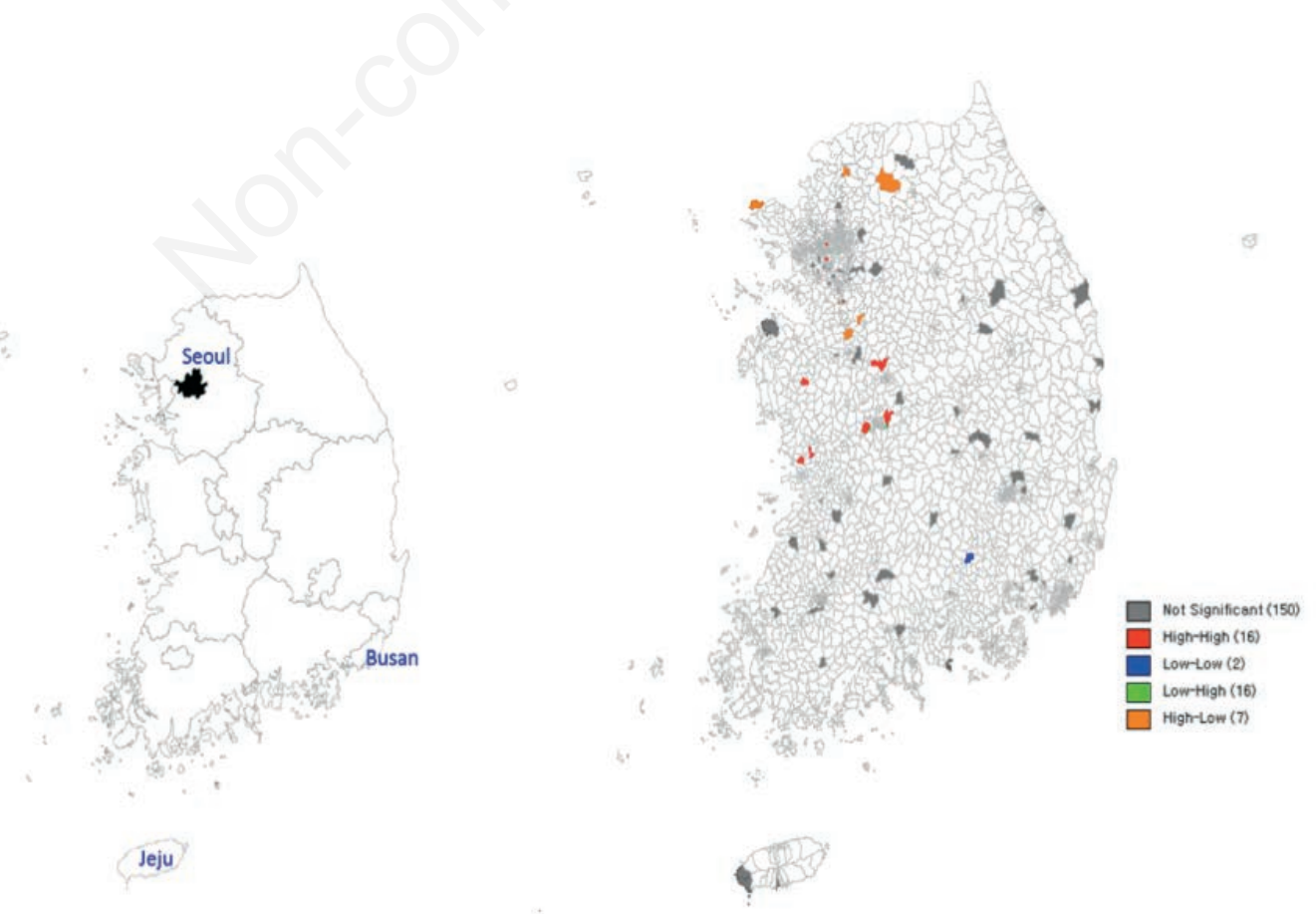

Figure 4. The local indicator of spatial autocorrelation cluster map for body mass index in Korea. 
variable was not significant in the SEM model. For the variables Flexibility activity days, Waist circumference and Smoking status, non-smoking contrasted with the reference level; for Drinking frequency, more than 4 times per week contrasted with the reference level; Age, Years of education and Muscle-strengthening activity days were statistically significant at the $10 \%$ level in the OLS model as well as in the SEM model. The increases in Flexibility activity days and Waist circumference, Non-smoking and Drinking more than 4 times per week tended to be associated with an increase in BMI, while the increases in Age, Years of education and Muscle-strengthening activity days tended to be related to a decrease in BMI.

\section{Discussion}

Obesity remains a global public health concern. Both central and local governments focus on obesity prevention by enforcing their own regional public health care plans. The management of public sports facilities is one of the local council plans in Korea. For councils, it is important to identify the effects of the number of public sports facilities on regional obesity. In this study, we investigated the spatial characteristic of BMI and the spatial effects of the number of public sports facilities on the average BMI in Korean regions.

First, we identified that Korea exhibits spatial dependence in BMI using the global Moran's I statistic. In addition, the residual of OLS model for the BMI showed significant positive spatial autocorrelation. Next, the spatial clusters and spatial outliers were then determined using a LISA analysis. This showed that Midwest Korea had high BMI in general, while the Seoul metropolitan area included several HH clusters and LH outliers.

Finally, we conducted various spatial regression models, and identified that the number of public sports facilities is not significantly related to BMI. This result could be caused by the low utilization ratio of public sports facilities and the unbalanced spatial distribution in number and the kinds of public sports facilities available. Therefore, councils try to i) increase the quality of public

Table 5. Comparison of the six models.

\begin{tabular}{|c|c|c|c|c|c|c|}
\hline & OLS & SLM & SDM & SEM & SDEM & GSM \\
\hline $\mathrm{AIC}$ & 321.690 & 323.510 & 319.330 & 308.230 & 317.110 & 308.790 \\
\hline Log likelihood & -140.843 & -140.757 & -120.666 & -133.116 & -119.554 & -132.397 \\
\hline Rho & - & -0.083 & -0.187 & - & - & -0.323 \\
\hline P-value & & 0.678 & 0.564 & & & 0.302 \\
\hline Lambda & - & - & - & 0.642 & -0.783 & 0.668 \\
\hline P-value & & & & $<0.000$ & 0.110 & $<0.000$ \\
\hline
\end{tabular}

OLS, Ordinary least square; SLM, spatial lag model; SDM, spatial Durbin model; SEM, spatial error model; SDEM, spatial Durbin error model; GSM, general spatial model .

Table 6. Results of ordinary least squares and spatial error model.

\begin{tabular}{|c|c|c|c|c|}
\hline \multirow[t]{2}{*}{ Variables } & \multicolumn{2}{|c|}{ OLS } & \multicolumn{2}{|c|}{ SEM } \\
\hline & Estimate & P-value & Estimate & P-value \\
\hline Intercept & 23.558 & $<0.000$ & 23.508 & $<0.000$ \\
\hline Age & -0.253 & 0.001 & -0.253 & 0.000 \\
\hline Years of education & -0.262 & 0.001 & -0.263 & 0.000 \\
\hline Number of members in household & 0.095 & 0.087 & 0.077 & 0.122 \\
\hline The average monthly household income & 0.018 & 0.711 & 0.015 & 0.721 \\
\hline Average hours of sleep & -0.045 & 0.295 & -0.026 & 0.498 \\
\hline Vigorous physical activity days & -0.044 & 0.348 & -0.043 & 0.299 \\
\hline Walking days & 0.023 & 0.624 & -0.010 & 0.818 \\
\hline Muscle-strengthening activity days & -0.110 & 0.044 & -0.096 & 0.048 \\
\hline Flexibility activity days & 0.110 & 0.066 & 0.132 & 0.013 \\
\hline Waist circumference & 0.666 & $<0.000$ & 0.704 & $<0.000$ \\
\hline Number of public sports facilities & 0.039 & 0.367 & 0.032 & 0.411 \\
\hline Number of public sports facilities per 10,000 people & -0.024 & 0.605 & 0.000 & 0.995 \\
\hline Smoking status:* Non-smoking & 0.245 & 0.091 & 0.308 & 0.018 \\
\hline Annual drinking frequency:* Less than once per month & -0.061 & 0.616 & -0.037 & 0.734 \\
\hline Annual drinking frequency: Once per month & -0.163 & 0.449 & -0.154 & 0.423 \\
\hline Annual drinking frequency: 2-4 times per month & -0.047 & 0.663 & -0.051 & 0.598 \\
\hline Annual drinking frequency: 2-3 times per week & -0.003 & 0.987 & 0.109 & 0.557 \\
\hline Annual drinking frequency: More than 4 times per week & 0.956 & 0.087 & 1.230 & 0.013 \\
\hline
\end{tabular}

*Reference level: Smoking status (Smoked more than 100 cigarettes during lifetime), Annual drinking frequency (None). OLS, Ordinary least square; SEM, spatial error model. 
sports facilities; ii) investigate the preferred types of public sports facilities and push for their establishment; and iii) incorporate the accessibility and needs of local residents in the selection and optimal location of new public sport facilities.

We set the unit of analysis as enumeration district and not as participant residence in this study because personal information was protected. Although our results are significant, data considering participant's residences would provide more accurate and meaningful results. Further studies analyzing more detailed and abundant data may provide results that are more accurate.

\section{Conclusions}

The decreases in age, years of education, and muscle-strengthening activity days, the increases in waist circumference and flexibility activity days, non-smoking status, and drinking more than 4 times per week were found to be significantly associated with the increase in BMI according to the SEM model. Based on these results, we can suggest doing muscle-strengthening activity more than doing flexibility activity to achieve a healthy BMI. In addition, shorter waistlines and reduced drinking would be recommended to people in general as a change in this direction would lead to a healthier lifestyle. Young age, low education level and non-smoking status need to be further investigated in terms of the relation with BMI.

\section{References}

Addo J, Smeeth L, Leon DA, 2009. Obesity in urban civil servants in Ghana: association with pre-adult wealth and adult socioeconomic status. Public Health 123:365-70.

Akaike H, 1974. A new look at the statistical model identification. Ieee T Automat Contr 19:716-723.

Akaike H, 1998. Information theory and an extension of the maximum likelihood principle. In: Akaike H, ed. Selected papers of Hirotugu Akaike. New York, NY: Springer. pp 199-213.

Anselin L, Bera AK, 1998. Spatial dependence in linear regression models with an introduction to spatial econometrics. Statist Textbooks Monographs 155:237-90.

Anselin L, 2004. Exploring spatial data with GeoDaTM: a workbook. Urbana 51:61801.

Anselin L, 2013. Spatial econometrics: methods and models. New York, NY: Springer Science and Business Media.

Berger IE, O'Reilly N, Parent MM, Séguin B, Hernandez T, 2008. Determinants of sport participation among Canadian adolescents. Sport Manag Rev 11:277-307.

Beydoun MA, Wang Y, 2009. Gender $\square$ ethnic disparity in BMI and waist circumference distribution shifts in US adults. Obesity 17:169-76

Bullough S, Davies LE, Barrett D, 2015. The impact of a community free swimming programme for young people (under 19) in England. Sport Manag Rev 18:32-44.

Chen DR, Wen TH, 2010. Elucidating the changing socio-spatial dynamics of neighbourhood effects on adult obesity risk in Taiwan from 2001 to 2005. Health Place 16:1248-58.

Downward P, Dawson A, Dejonghe T, 2009. Sports economics. London: Routledge.

Downward P, Rasciute S, 2010. The relative demands for sports and leisure in England. Eur Sport Manag Q 10:189-214.

Drewnowski A, Rehm C, Kao C, Goldstein H, 2009. Poverty and childhood overweight in California Assembly districts. Health Place 15:631-5.

Drewnowski A, Rehm CD, Arterburn D, 2014. The geographic distribution of obesity by census tract among 59767 insured adults in King County, WA. Int J Obesity 38:833-9.

Duncan DT, Castro MC, Gortmaker SL, Aldstadt J, Melly SJ, Bennett GG, 2012. Racial differences in the built environmentbody mass index relationship? A geospatial analysis of adolescents in urban neighborhoods. Int J Health Geogr 11:1.

Han K, Park S, Symanzik J, Choi S, Ahn J, 2016. Trends in obesity at the national and local level among South Korean adolescents. Geospat Health 11:130-6.

Han EJ, Sohn SY, 2017. An analysis on spatial autocorrelation between increased foreigners and residential mobility in Seoul. J Korea Plan Assoc 52:201-24.

Holman CD, Donovan RJ, Corti B, 1996. Factors influencing the use of physical activity facilities: results from qualitative research. Health Promot J Aust: Off J Austral Assoc Health Prom Profess 6:16-21.

Højgaard B, Olsen KR, Søgaard J, Sørensen TI, Gyrd-Hansen D, 2008. Economic costs of abdominal obesity. Obesity Facts 1:146-54.

Huelsenbeck JP, Crandall KA, 1997. Phylogeny estimation and hypothesis testing using maximum likelihood. Ann Rev Ecol Syst 28:437-66.

Kang HT, Lee HR, Lee YJ, Linton JA, Shim JY, 2013. Relationship between employment status and obesity in a Korean elderly population, based on the 2007-2009 Korean National Health and Nutrition Examination Survey (KNHANES). Arch Gerontol Geriat 57:54-9.

Kang K, Sohn SY, 2016. Relationships between nutrient patterns and geodemographic characteristics in Korea. Nutr Diet 73:427-32.

Kumanyika S, Jeffery RW, Morabia A, Ritenbaugh C, Antipatis V, 2002. Obesity prevention: the case for action. Int J Obesity 26:425-36.

Mak KK, Kim DH, Leigh JP, 2015. Sociodemographic differences in the association between obesity and stress: A propensity Score-Matched Analysis from the Korean National Health and Nutrition Examination Survey (KNHANES). Nutr Cancer 67:804-10.

Moran PA, 1950. Notes on continuous stochastic phenomena. Biometrika 37:17-23.

Myers CA, Slack T, Martin CK, Broyles ST, Heymsfield SB, 2015. Regional disparities in obesity prevalence in the United States: A spatial regime analysis. Obesity 23:481-7.

Niclasen B, Petzold M, Schnohr CW, 2012. The association between high recreational physical activity and physical activity as a part of daily living in adolescents and availability of local indoor sports facilities and sports clubs. Scand J Public Health 40:614-20.

OECD, 2013. Overweight and obesity. OECD Factbook 2013 Economic, Environmental and Social Statistics.

O’Reilly N, Berger IE, Hernandez T, Parent MM, Séguin B, 2015. Urban sportscapes: An environmental deterministic perspective on the management of youth sport participation. Sport Manag Rev 18:291-307.

Pouliou T, Elliott SJ, 2010. Individual and socio-environmental determinants of overweight and obesity in Urban Canada. 
Health Place 16:389-98.

Ross NA, Tremblay S, Khan S, Crouse D, Tremblay M, Berthelot JM, 2007. Body mass index in urban Canada: neighbourhood and metropolitan area effects. Am J Public Health 97:500-8.

Prins RG, van Empelen P, Te Velde SJ, Timperio A, van Lenthe FJ, Tak NI, Crawford D, Brug J, Oenema A, 2010. Availability of sports facilities as moderator of the intention-sports participation relationship among adolescents. Health Educ Res 25:48997.

Ruseski JE, Humphreys BR, Hallmann K, Breuer C, 2011. Family structure, time constraints, and sport participation. Eur Rev Aging Phys A 8:57.

Sallis JF, Prochaska JJ, Taylor WC, 2000. A review of correlates of physical activity of children and adolescents. Med Sci Sport Exer 32:963-75.

Slack T, Myers CA, Martin CK, Heymsfield SB, 2014. The geographic concentration of US adult obesity prevalence and associated social, economic, and environmental factors. Obesity 22:868-74.

Sotiriadou K, 2009. The Australian sport system and its stakeholders: development of cooperative relationships. Sport Soc
12:842-60.

Stommel M, Schoenborn CA, 2010. Variations in BMI and prevalence of health risks in diverse racial and ethnic populations. Obesity 18:1821-6.

Ståhl T, Rütten A, Nutbeam D, Bauman A, Kannas L, Abel T, Lüschen G, Rodriquez DJA, Vinck J, van der Zee J, 2001. The importance of the social environment for physically active lifestyle-results from an international study. Soc Sci Med 52:1-10.

Van Lenthe FJ, Brug J, Mackenbach JP, 2005. Neighbourhood inequalities in physical inactivity: the role of neighbourhood attractiveness, proximity to local facilities and safety in the Netherlands. Soc Sci Med 60:763-75.

Wen TH, Chen DR, Tsai MJ, 2010. Identifying geographical variations in poverty-obesity relationships: empirical evidence from Taiwan. Geospat Health 4:257-65.

Wicker P, Hallmann K, Breuer C, 2013. Analyzing the impact of sport infrastructure on sport participation using geo-coded data: evidence from multi-level models. Sport Manag Rev $16: 54-67$ 